\title{
Problems and Countermeasures of College English Practice Teaching Mode under the New Situation
}

\author{
Li Siping \\ Yangtze University, School of Foreign Studies, Hubei, China, 430040
}

Keywords: College English practice teaching; problem; countermeasure

Abstract: At present, college English practice teaching has the disadvantages of insufficient interaction between teachers and students in teaching, including heavy knowledge, light application, outdated teaching methods, improper use of multimedia teaching methods and single evaluation method. The following countermeasures should be taken: student-oriented, constructing a harmonious and harmonious teacher-student relationship; transforming the tendency of heavy knowledge and light application, cultivating students' communicative and linguistic application skills; scientifically improving teaching methods; rationally using multimedia teaching methods; updating traditional evaluation the way.

\section{Current problems in college English practice teaching}

\subsection{Insufficient interaction between teachers and students in teaching}

Educator Rubin said that language is a skill that can only be obtained through the efforts of the learner himself. However, at present, there is still a phenomenon of excessively magnifying the dominant position and role of teachers in college English practice teaching. Teachers are the masters of the classroom, determining the teaching content and teaching methods. They are accustomed to the "filling the duck" style of "full house irrigation" teaching, one stop When I went to the podium, I couldn't know that students were the main body of learning activities. Students are passively accepted in the classroom and the teachers' explanations are all collected. They are used to burying their heads in class notes and they are afraid to miss any content that the teacher said. The consequence of this kind of teacher-centered classroom teaching is to suppress the students' enthusiasm for learning, form a passive situation in which students can't learn without teaching and students follow the teacher step by step. Their subjective initiative and independent learning ability can't be improved. In addition, such classrooms lack teacher-student interaction and communication, resulting in a distant relationship between teachers and students, unable to form a harmonious and harmonious classroom atmosphere and the teaching effect is not satisfactory ${ }^{[1]}$.

\subsection{Heavy knowledge, light application}

In the classroom, the teacher focuses on the explanation of the language. The practice is also a repetitive practice around the language. It does not pay attention to the students' practical use of language and communication skills. In this way, the living verbal communication and 
communication that should be in the classroom teaching are replaced by the boring language knowledge lectures. The classroom is not very interesting and the atmosphere is dull. It is also understandable why Chinese college students are good at all kinds of written test English exams, but they are fearful and timid about listening and speaking tests. Chinese college students' "dumb English" and "scorpion English" have also been a common problem that has been criticized. Such classroom teaching cannot achieve the teaching objectives proposed by the "Teaching Requirements", nor can it improve students' language application and communication skills ${ }^{[2]}$.

\subsection{Old teaching methods}

Due to the backward teaching concept, the teaching methods of some college English teachers are unchanged: the teaching process is to preview, explain and practice in a round-the-clock manner; the teaching steps are first of all vocabulary explanation, then lead the students to translate, understand the texts word by word and explain the language knowledge points. And grammar points and finally lead students to do after-school exercises and even some teachers in the practice session is just the right answer. Throughout the teaching process, the teachers have a big package and even the student activity teachers who are designing the textbooks are also "on the job", lest the students can't answer or make mistakes. For students, as long as they follow the pace of the teacher step by step, this kind of classroom teaching that students do not feel the pressure makes students lack motivation to learn. On the surface, the teacher has completed the prescribed teaching tasks according to the progress of the teaching. However, the teacher does not understand how much the students really master or how the application is used. After one semester, the students are also finished with ignorance and the result is "water through the ground". Such teaching cannot exert the subjective initiative of students, nor can they cultivate their ability to learn independently ${ }^{[3]}$.

\subsection{Improper use of multimedia teaching methods}

At present, colleges and universities have basically popularized multimedia-assisted instruction, but some old teachers have become accustomed to the teaching mode of "a chalk, a mouth, a blackboard and a book" and are reluctant to learn to use modern language teaching equipment. Practice has proved that traditional teaching methods can't provide students with a large number of modern language information and audio-visual, real language environment. In addition, many institutions have the phenomenon of unreasonable use of multimedia-assisted teaching: some teachers sit at the computer after the whole class, just presenting and teaching courseware content and have no time to take into account the students' reaction and classroom order; some teachers rely too much on multimedia. There is even a situation in which it is impossible to go to class after leaving multimedia; some teachers produce courseware that is fancy and complicated, but there are many invalid information; some teachers guarantee the projection effect, turn off the lights, pull up the curtains and teach in dim light. Causes the student to be drowsy. These phenomena show that in English teaching, the value of multimedia-assisted instruction is not truly reflected and students' expectations for multimedia English practice teaching cannot be met ${ }^{[4]}$.

\section{Countermeasures for the reform of college English practice teaching}

\subsection{Student-oriented, establish a harmonious and interactive teacher-student relationship}

Student-oriented classroom teaching is lively and lively. Teachers should implement the teaching philosophy that students are the main body of learning and design colorful classroom activities as much as possible to make the classroom a place for language practice. Teachers should no longer be 
the master of the classroom, but must find ways to mobilize the enthusiasm, initiative and creativity of students, so that students can participate in classroom teaching activities; students should change the passive acceptance of the situation, play a subjective initiative, enhance learning interest, Improve language skills. In the student-oriented classroom, the teacher-student relationship will become harmonious and harmonious. Teachers are the promoters of students' self-learning. When students are successful, teachers should give encouragement and propose new goals. When students encounter confusion, teachers should create situations and create a positive psychological atmosphere, so that students can overcome in trust. Difficulties, motivated and encouraged. Teachers and students, students and students should exchange and discuss the content of the teaching and thus generate thinking and research. Such teaching transforms the teacher's scholasticism in the traditional sense into the participation of teachers and students, forming a true "learning community", thus establishing a democratic and harmonious teacher-student relationship ${ }^{[5]}$. The countermeasures for the reform of college English practice teaching are shown in Figure 1.

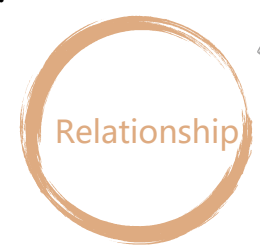

Establish teacher-student relationship

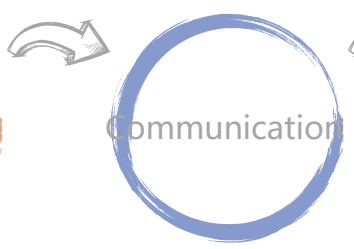

Transforming the tendency of heavy knowledge and light application

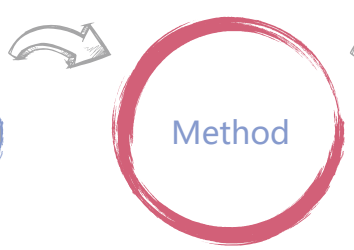

Choosing the right teaching method

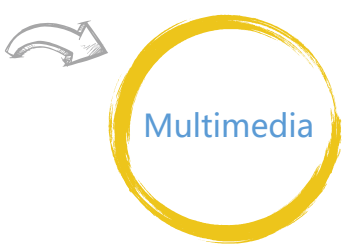

Reasonable use of multimedia teaching methods

Figure 1 Countermeasures for the Reform of College English Practice Teaching

\subsection{Transforming the tendency of heavy knowledge and light application, in order to cultivate students’ English communication and language application ability}

Language is a tool for communication. Teachers should change the teaching philosophy and reform teaching methods and methods. First, teachers should consider how to combine language knowledge and application when designing each teaching session. Second, teachers need to improve their ability to control classroom activities. Teachers are not only the knowledge transferrers, but also the guides, organizers and participants of classroom teaching activities, the analysts and consultants of students' learning needs and characteristics, the feedback of learning effects and the teachers should encourage and guide students to participate actively. Class activities, dare to express. Finally, teachers need to develop students' intercultural communication skills. The necessary cross-cultural knowledge education is indispensable. The differences between English and Chinese are large and the cultural connotations behind the language are also very different. Students are mainly in exam-oriented education at the secondary level and their pragmatic competence is generally poor. If the college English class still cannot develop students' intercultural communication skills, it is difficult for students to use English accurately when they enter the society.

\subsection{Choosing the right teaching method}

The communicative teaching method and the task-based teaching method can reflect the students’ 
main body of learning and are conducive to the cultivation of language use ability. Integrating communication and communication elements into the explanation of teachers' language and cultural knowledge, teachers can provide students with a large number of opportunities for active learning, participation in discussions and mutual exchanges through image display, problem discussion and knowledge point induction. Task-based approach can achieve teaching goals through one or more specific activity tasks, which not only mobilizes students' enthusiasm and enhances their sense of accomplishment, but also enables students to learn and understand the language effectively. The teacher breaks down the learning tasks in each link into several parts and arranges them in the form of individuals or groups according to the difficulty level and the characteristics of the students and establishes relevant incentive mechanisms. This measure will stimulate the enthusiasm of students, students of different levels. They are willing to participate, collect information and prepare carefully. They hope to complete the task satisfactorily and get the recognition and encouragement of the teachers. These forms not only greatly satisfy the students' curiosity, stimulate the enthusiasm of learning, turn the external motivation of English learning into intrinsic motivation, but also help students improve their communication and communication skills. Students' participation in the classroom has increased and naturally the students' self-learning ability has also improved. However, this does not mean that teachers can completely let go. Teachers should pay attention to individual differences in the teaching process, meet the learning needs of different students and enable students to find suitable learning methods with the help of teachers.

\subsection{Reasonable use of multimedia teaching methods}

Compared with traditional classroom teaching, multimedia assisted instruction has many advantages. On the one hand, in the close to the real language environment, language teaching is presented in three different ways through different means of sound, image, light, electricity, etc. Students' various cognitive organs can be fully mobilized and students of different levels can Get the satisfaction of cognition. Multimedia technology makes classroom teaching activities more vivid and intuitive, students can actively participate and can learn and practice language and improve application ability under the guidance of teachers. On the other hand, under the condition of multimedia-assisted teaching, the amount of information of language materials is larger and the film and television clips, information and social and cultural background knowledge related to the lecture content can be transmitted through multimedia presentation. The development trend of multimedia teaching equipment is shown in Figure 2.

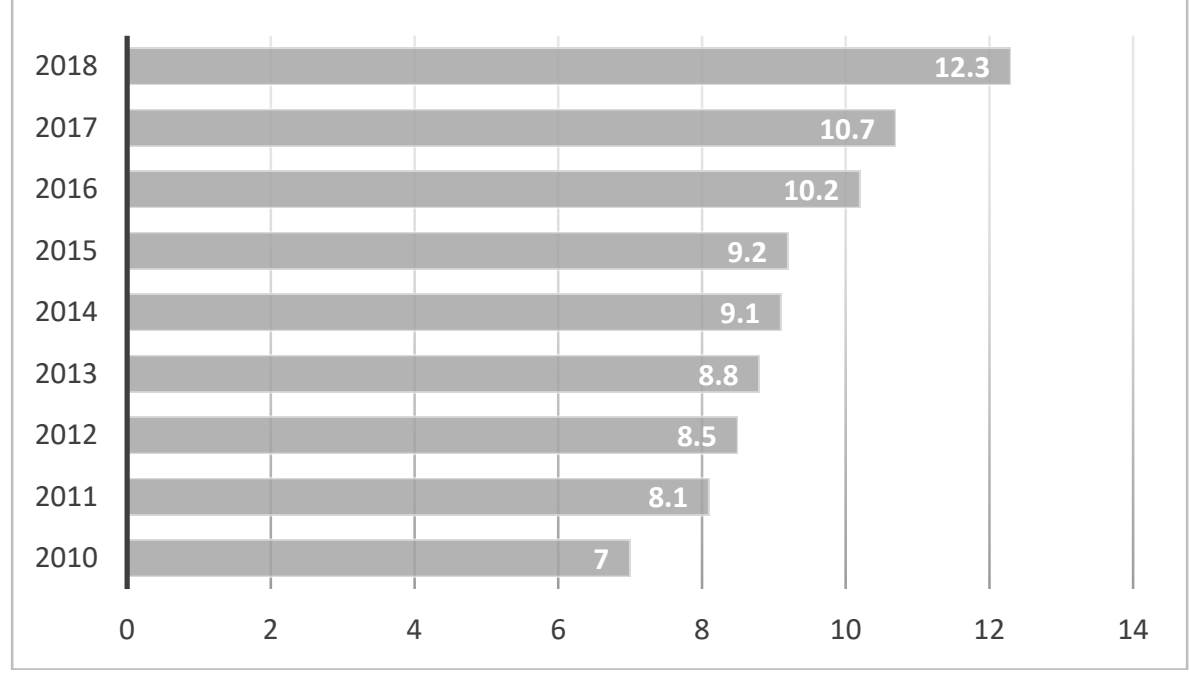

Figure 2 Development trend of multimedia teaching equipment 


\section{Conclusion}

Of course, teaching can't rely entirely on multimedia. After all, this is only an aid. Traditional teaching methods can't be completely abandoned. Teachers can guide students to understand, appreciate and understand sentence by sentence. To the original language beauty. The combination of traditional teaching methods and multimedia-assisted instruction is reasonably compatible and can complement each other and complement each other.

\section{References}

[1] Ma Liwei, Chen Zhiyong, Jing Zhihua. Study and practice of website-assisted college English teaching [P]. Information Networking and Automation (ICINA), 2010 International Conference on, 2010.

[2] Yang Pei Cong. The teaching practice in Comprehensive College English Course-Based on the Integrated Language Approach[P]. Computer Science and Service System (CSSS), 2011 International Conference on, 2011.

[3] Yang Hui. Study and practice based on computer-aided College English teaching [P]. IT in Medicine and Education (ITME), 2011 International Symposium on, 2011.

[4] Liu Shuang. Practice on Level-based College English Teaching Model under CALL Environments [P]. Computer Distributed Control and Intelligent Environmental Monitoring (CDCIEM), 2012 International Conference on, 2012.

[5] Gu xiaoyu. A Study and Practice of the Internet Application in College English Teaching [J]. Energy Procedia, 2011, 13. 